\title{
CORRECTION
}

\section{Correction to: Soil dust effects on morphological, physiological and biochemical responses of four tree species of semiarid regions}

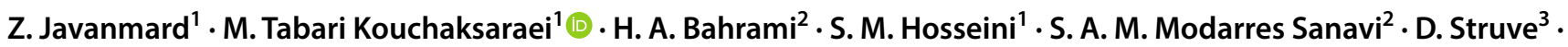 \\ C. Ammer ${ }^{4}$
}

Published online: 4 June 2020

(c) Springer-Verlag GmbH Germany, part of Springer Nature 2020

\section{Correction to: \\ European Journal of Forest Research (2020) 139:333-348 \\ https://doi.org/10.1007/s10342-019-01232-z}

In the original publication of the article the seventh author name was incorrectly published. The correct name is given in this correction.

Publisher's Note Springer Nature remains neutral with regard to jurisdictional claims in published maps and institutional affiliations.

The original article can be found online at https://doi.org/10.1007/ s10342-019-01232-z.

M. Tabari Kouchaksaraei mtabari@modares.ac.ir

1 Faculty of Natural Resources and Marine Sciences, Tarbiat Modares University, Noor, Mazandaran 46417-76489, Iran

2 Faculty of Agriculture, Tarbiat Modares University, Tehran, Iran

3 Horticulture and Crop Science, The Ohio State University, 386 E Torrence Road, Columbus, OH 43214, USA

4 Silviculture and Forest Ecology of the Temperate Zones, Georg-August-Universität Göttingen, Göttingen, Germany 